\title{
Implementation of Database Using Python Flask Framework
}

\author{
Mandeep Singh ${ }^{1}$, Ayushi Verma ${ }^{2}$, Aashwaath Parasher ${ }^{3}$, Nidhi Chauhan ${ }^{4}$, Gaurav Budhiraja ${ }^{5}$ \\ ${ }^{1}$ Assistant professor \\ Department of computer science and engineering HMRITM,India \\ 2,3,4,5 UG student \\ Department of Electronics and Communication Engineering HMRITM,India
}

\begin{abstract}
This paper is aimed at development of a college database management system that can be used in any educational institution. Python flask framework is used to implement this application, that can be accessed throughout the institution or by any specific department of the institution. This system offers different features to the students and the members of the staff which includes attendance and marks of the students that can be accessed by both student and staff but can be only updated by staff of particular department . Students as well as staffs have separate logins that can be accessed by them easily. This system also includes a library management system which works in real time, a micro transport management system and a training and placement management system. This system is developed to maintain and facilitate easy access to information to every member associated with this system. For this the users must be registered with the system after which they can access their accounts as well as modify data as per the permissions given to them.
\end{abstract}

Keywords—python, flask framework, implementation,

\section{I .Introduction}

The title of the project is "Implementation of College Management System Using Python Flask Framework"as the title defines, that the college management system is an application based on python flask framework and it's aim is to provide all levels of management of information within an organization.

The college management system is a software that is designed to manage all the day-to-day activities of students and staff in an automated, organized and integrated form. This helps colleges and universities to save time, money and resources.

For a student and staff the Administrator of system creates login id \& password, using these student and staff can access the system to either update or view some information from the database.

The purpose of this document is to describe the functionality, requirements and general interface of the College Management System.

The front end software we uses is html, css and java script. For backend python flask and mysql are used.
Python flask framework is the technology that we are using to develop the college management system. Flask is a web framework written in python. It can be classified into micro framework because it does not require any particular tools or libraries and has inbuilt database. It has no database abstraction layer. However flask support extension that can add application features. Extensions exist for objectrelational mappers, form validation, upload handling, various open authentication technologies and several common framework related tools. Extensions are updated far more frequently than the core Flask program.

The database refers to a collection of records that manage to produce useful information. The data can be accessed, modified, managed, controlled and organized to perform various data-processing operations. The data is usually indexed across rows, columns and tables that make workload processing and data querying efficient.

There are different types of databases which are of following types:

- Object-Oriented

- Relational

- Distributed 


\section{- Hierarchical}

- Network

Database Management System (DBMS) refer to the technology solution used to improve and manage the storage and get back of data from databases. DBMS offers a systematic approach to manage databases by an interface for users as well as accessing the databases by apps.

\section{Python flask framework features}

1) It Contains development server and debugger

2) It depend on two external libraries:

- the Jinja2 template engine -the Werkzeug WSGI toolkit.

3) It provides the Integrated support for unit testing

4) It also provides restful request dispatching

5) It is very easy to deploy Flask in production

6) Flask provide HTTP request handling functionality

7) It is highly flexible, the configuration is even more flexible than that of Django, giving you plenty of solution for every production need.

In overall, Flask is one of the most polished and feature-rich micro frameworks available. Flask has a thriving community with best extensions, and an graceful API. Flask comes with all the benefits of fast templates, strong WSGI features, thorough unit testability at the web application and library level, extensive documentation.

\section{Literature Review}

There are some number of researchers who research in the field of flask framework and database management system (DBMS) for college management system :

Sagar Pawar, Gaurav Geet, Pavan Sonawane, Chetan B.Bharte proposed a college ERP system- In a college there are various sections and each section handles all students' information. These sections are connected with each other. The existing system of a number of college is having issues of interlinking data.

Krithi P, Dr M Ramakrishna, proposed Student Management System- They created Student Management System for smooth treatment of data identified with students. It is basic for an institute or to a university or to a college, which uses PC, additionally which decreases labor. Student Management System deals with a few student subtle elements like USN, student attendance, internal evaluation marks, parent name, telephone number, email-id, date-of-birth, class, sex and so on.

Lalit Mohan Josh- proposed a College Management System (C.M.S) based on Intranet. This framework might be utilized for observing attendance for the college. Student and in addition staffs logging in may likewise get to or can be look through any of the data with respect to college. Attendance of the staff and students as well as marks of the students is updated by staff.

Megha Goel,Ankita Wasnik, Ashwini Gulhane, Swati Gajarlewar, Yogita Rasekar, proposed a"College Monitoring System"- This system developed by using $\mathrm{PhP}$, SQL server, Java script and HTML. Most of the colleges maintain student information in the records. At the point when the quantity of records expanded, it is a tedious activity to keep up the data of every student in the current manual system. Keeping up the records physically prompts blunder inclined and required more labor and it devours more opportunity for preparing the records.

Vishwakarma R Ganesh , proposed "Android College Management System- In this paper, he has advanced an android utility so one can be useful in college management system. In his system students can view results by the use of android telephones. The data has been saved at college server. The faculty can login into their college account through the app itself and update the academic result. On this system, students have clean get right of entry to for viewing the marks, furnished their authentications are correct and they're now not approved to alternate/replace the marks.

\section{System Design}

The system design contains features, and working of the system. There is a flow diagram also which give the overview of the system work. In this system there are two type of user that is student and the staff. These users have many features through which they can view or see and upload the information but there is a restriction also that staff registration can only be done by registered staff. Student can only view not upload or change the information.

But staff can view, upload and delete the record. The college management system can be used to manage the data of all type of educational institutes. The system uses python flask framework. The main modules involved in this system are:

- Login

- WT Forms

- Window

Some of the features of the proposed system given to the student and the staff are:

- Student login

- Student registration

- View attendance 
- View result

- View library records

- Staff login

- Staff registration

- Update attendance

- Transport management

- Update result

- Update library records

- Training and placement management

Flow diagram of student database:

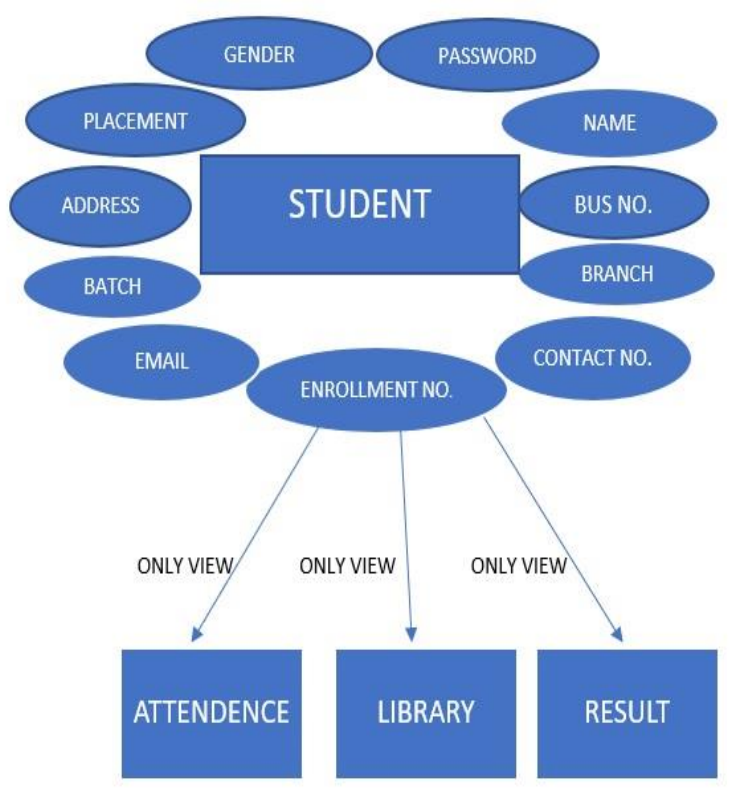

Above is the flow diagram of the student database which shows the different attributes of the student registration process and the features they can use or go through. To use the features student need to register first. In the registration process he or she need to enter the name, enrollment number, email, contact number, batch gender and password. After registration is done, student can login by entering the enrollment number and use the feature. By entering the enrollment number student can check the attendance update, result and library update.

In attendance feature student can check the number of classes he or she attend and depending on the classes they attend there is a total attendance column which shows the total percentage of the attendance.

In library feature student can check the issue date and fine.

Student cannot update or change the attendance details, library details and result details.

Flow diagram of staff database:

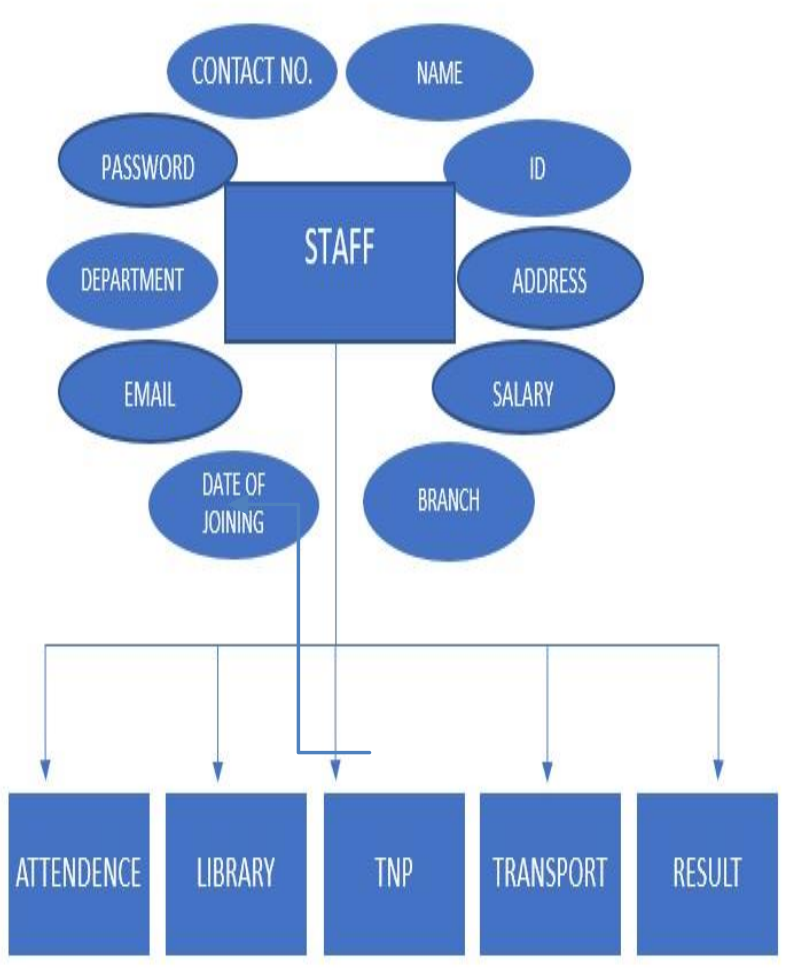

Above is the flow diagram of the staff which shows the different attributes of the staff registration process and the feature they use or go through. to use the feature staff need to register first but registration of the staff can be done by the registered staff only. In the registration process, the registered staff needs to login first by entering the id and the password after that he or she can do the registration. For the registration staff needs to enter the name, address, contact number, email, date of joining, department, salary and id.

After the registration is done staff can view or upload the information. In the attendance feature staff member can upload the attendance of the student and in the library feature staff can add details like the book name, issued date, author name and fine details. Third feature is the training and placement, in this, staff member can add the details about the company name and student name. fourth feature is the transport, in this they can enter the student route number and according their route they enter the bus number. Fifth feature is the delete records, they can delete the records of the students. They can also handle the staff and the student records.

Module wise description:

Login module is used to check whether the user is an authorized person to use the system or not. For this the user should give the correct user name and password.

This module consists of the following sub modules: 
- Student Registration

- Student attendance

- Student Marks

- TNP(training and placement)

- Employee Detail

- Employee Salary

- Employee ID

- Course Detail

- Library

- Transport

- Results

The Student Registration Form is designed for registering the new students details and course details. The Student Marks Form is designed for submitting the semester or exam marks of the students for a particular course or an individual student which can be accessed by both student and staff but can be only be updated by staff. The Student Id Form is used to create the identity number for each student for different course. The Employee details form is designed for entering the staff details and other relevant details. The Employee Id used to create the identity number for each staff member. The salary form is used to derive the salary for employees. The Course details form is designed for entering the different course available in the campus and other relevant details.

\section{Reports}

All the above mentioned data are stored in the back end and can be retrieved as reports with filtering options. The Following are the reports can be taken from this system

- Student Report

- Employee Report

- Attendance Detail Report

- Book Detail Report

- Issued Book Report

- Fee Detail Report

- Marks Detail Report

- Generate library fine report

- Student placement report

- Student result

Overview of the system:

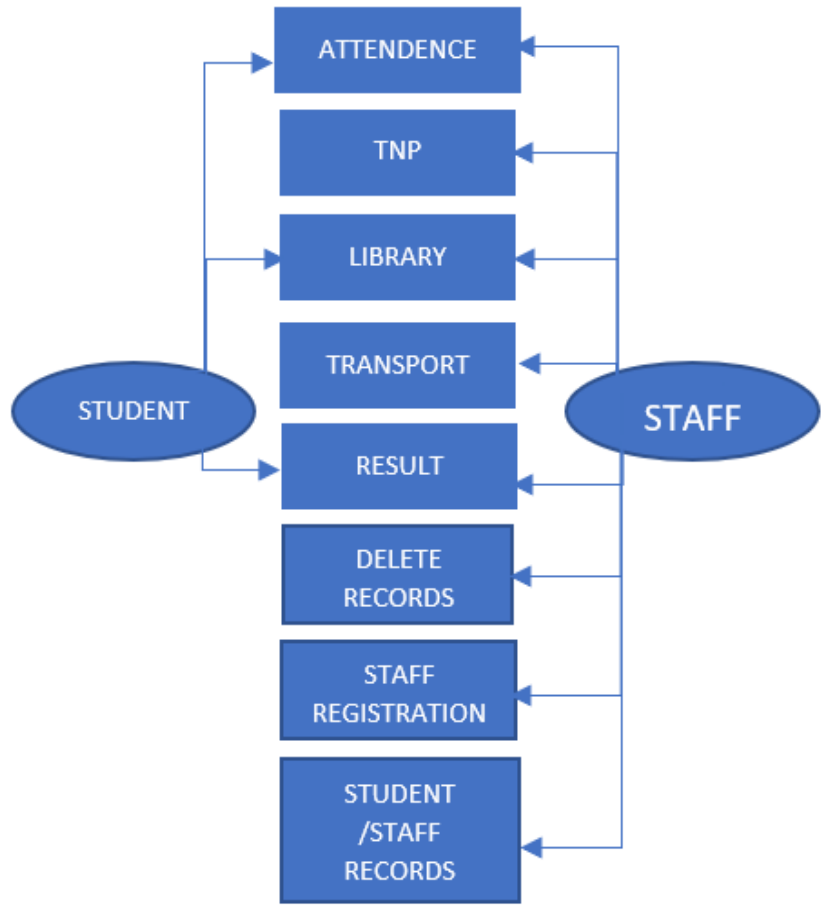

This is the overview of the system, which is the combination of the staff and student databases.

Front view of the system:

\section{Minor Project}

Welcome to College Management System This appication is buito on python farc framework

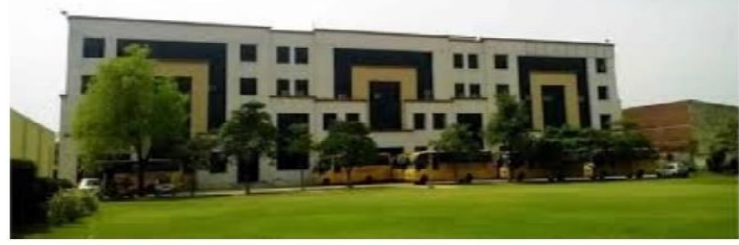

Front view of the system:

In the front page there are many option given:

- Home-

- About: In the about there is a brief description about the system

- Dashboard

- Update profile: In update profile, student or staff can update the profiles

- logout: In the logout option student can logout. 
View of the dashboard of the staff:

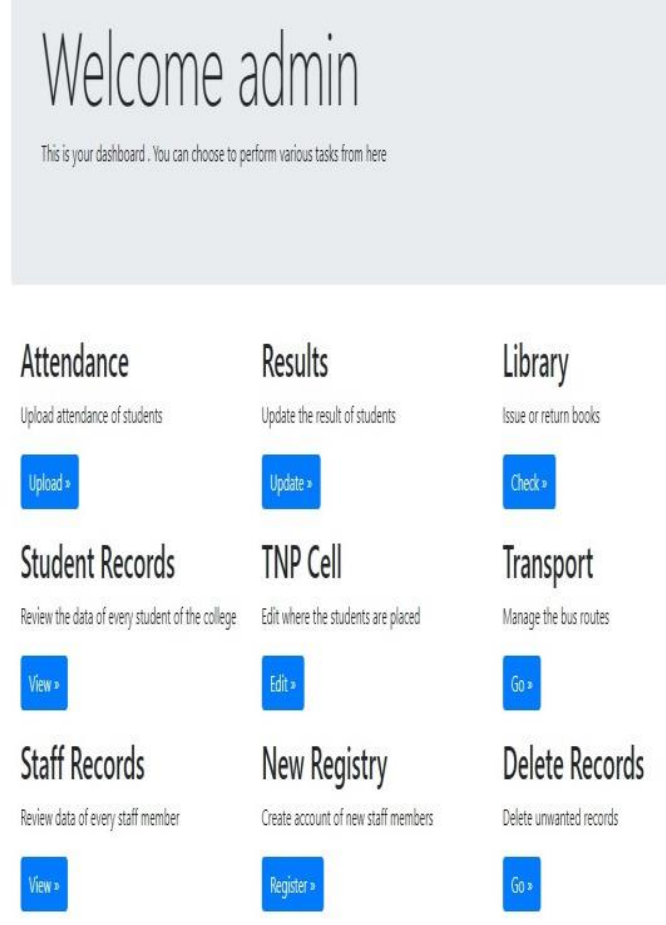

The staff dashboard shows various feature that is provided by the system. In the image admin is the registered staff name, the name is according the registered staff name. These all are the features they can update.

\section{CONCluSion}

The project is entitled as college management system is the system that deals with the problems related to the particular college or institution. This project is successfully

implemented with all the features mentioned in the system requirements specification. This system provide an information to the student and the staff according to the chosen service. This system is designed keeping in view the day to day problems faced by a college.

\section{I. References}

[1] Vishwakarma R Ganesh, "Android College Management System", International Journal of Advanced Research in Computer Engineering \& Technology (IJARCET) Volume 5, Issue 4, pp. 882-885,2016.J. I. S.

[2] Jacobs and C. P. Bean, "Fine particles, thin films and exchange anisotropy," in Magnetism, vol. III, G. T. Rado and H. Suhl,
Eds. New York: Academic, 1963, pp. 271350.

[3] Lalit Mohan Joshi, "A Research Paper on College Management System", International Journal of Computer Applications, Volume 122 ,No.11, pp. 32-44, 2015.

[4] Aishwarya Tamboli, Priti Shinde, Pravin Pariskar,"Institute Administration

Automation and Student Database Management System", International Journal of Advance Research, Ideas and Innovations in Technology,Volume3, Issue2, pp. 921925, 2017

[5] R. Rada, H. Mili, E. Bickneel and M. Bletner, "Development and application of a metric on semantic Nets," IEEE Transaction on system, Man and Cybernetics, Vol. 19, No. 1, 17-30, 1989

[6] Connoly, T. M., \& Begg, C. E. (2002). Database System, 3th Edition. London: University of Paisley.

[7] R. Richardson and A. F Smeaton, "Using wordnet in a knowledgebased approach to information retrieval," working paper, CA0395, School of computer application , Dublin city university, Ireland, 1995

[8] M. Young, The Technical Writer's Handbook. Mill Valley, CA: University Science, 1989.

[9] Ha n Han J W, Kamber M. Data Mining: Concepts and Techniques. San

[10] Francisco: CA. Morgan Kaufmann Publishers. 2001:2-4.

[11] Hand D, Mannila H, Smyth P. Principle of Date Mining, Cambridge, CA. MIT Press, 2001:1-2

[12] Andhra Pradesh, vol. 2, pp. 2342-2348, june 2013 Agrawal R, Srikant R. Privacy-Preserving Data Mining. ACM SIGMOD Conference on Management of Data.Dallas,Texas,2000.439-450.

[13] S.R.Bharamagoudar, Geeta R .B. and SG.Totad, "Web Based Student Information Management System"

[14] N. M. Z. Hashim and S. N. K. S. Mohamed, "Development of Student Information System", Universitiy Teknikal Malaysia Melaka, vol. 2, pp. 256 -260, August 2013.

[15] J Han, Y Cai, N Cercone. Knowledge Discovery in Database: An AttributeOriented Approach [M]. VLDB-92, Vancouver, British Columbia,Canada, 1992:547-559.

[16] X. X. Xin, R. M.Wu, and H. H.Li, “A faremework model of the e-campus 
management system based on SOA," in Proc.2009 International Conference on Computational Intelligence and Software Engineering Wuhan, 2009, pp. 1-3[4]

[17] H. M. Weiand L. J.He, "Constructing the comprehensive academic affairs management system based on SOA," in Proc. 2009 1stInternational Conference on Information Science and Engineering, Nanjing, Jiangsu, pp. 32613264.
[18] D B Heras, D. Otero,and F. Arguello,”An eco feedback system for impro ving the sustainability Performanceof universities," in Proc. 2011 IEEE International Conference on Virtual Environments Human

- Computer Interfaces and Measurement Systems, Ottawa, ON 2011 , pp. $1-6$. 